\title{
Cinema Gaúcho: diversidades e inovações
}

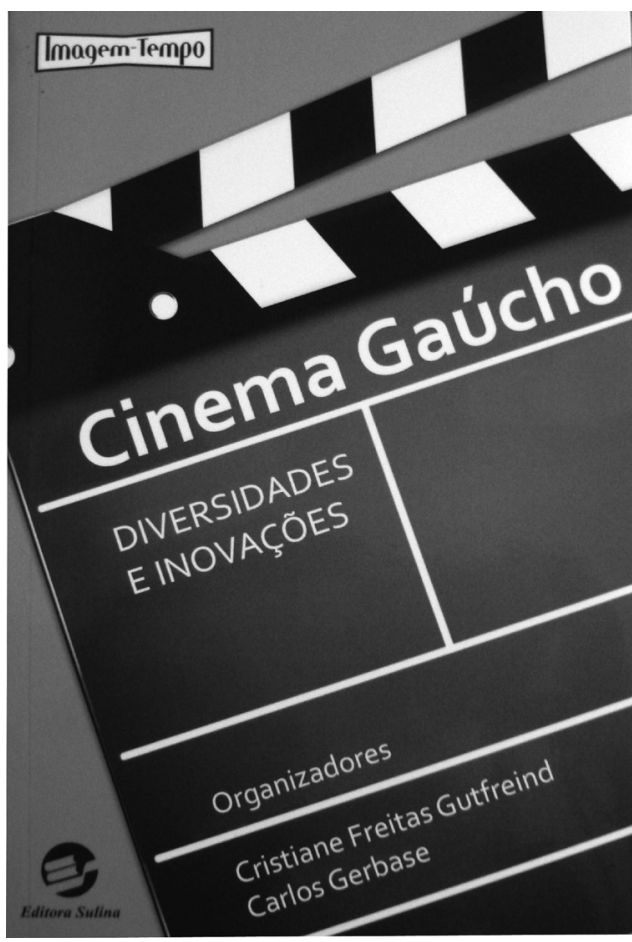

GUTFREIND, Cristiane Freitas; GERBA$\mathrm{SE}$, Carlos (Orgs.). Cinema Gaúcho: diversidades e inovações. (Série Imagem - Tempo). Porto Alegre: Sulina, 2009.

\section{Dafne Pedroso}

Doutoranda em Comunicação social/PUCRS/RS/BR dafnepedroso@gmail.com
Quem pesquisa sobre cinema gaúcho sabe a dificuldade que é encontrar informações sobre filmes, mercado, história, entre outros. Rastrear textos que tratem do assunto em bibliotecas, bancos de teses, revistas é atividade comum para quem se dedica a tal temática. Nesse sentido, encontrar um livro que reúne autores com diversas preocupações sobre o assunto já indica a importância de Cinema gaúcho: diversidades e inovações. A escassez de publicações que circulam é destacada na apresentação feita por Cristiane Freitas e Carlos Gerbase.

Os organizadores afirmam que a proposta do livro não seria um mapeamento e uma análise da produção, mas uma compilação de textos de autores que se debruçam sobre várias preocupações. De todo modo, há algo que os liga e que está prometido no título, ou seja, pensar o cinema gaúcho. Freitas e Gerbase lançam questões que consideram importantes sobre o tema, como "o cinema gaúcho tem identidade própria? Ele já pode ser chamado de indústria, ou continua sendo um artesanato? Ainda tem sentido fazer cinema brasileiro longe do eixo Rio-São Paulo?" (p. 7).

Minha proposta nesta resenha é a de identificar elementos que respondam a algumas dessas questões, pinçar, nos textos, parâmetros que sirvam para refletir sobre o que seria esse cinema gaúcho. Ainda que difícil, escorregadia e sempre complexa seja uma categorização, penso que os textos revelam dados para que possamos pensar nas especificidades desse cinema. É nessa proposta de identificar elementos, tateando, como também fazem os autores do livro, que orienta esta resenha. Ignoro a divisão sugerida entre inovações e diversidades (ainda que a compreenda) para pensar em elementos que perpassam todas as reflexões. Considere-se que o resumo que faço das ideias dos autores que armam o livro ressente no detalhamento dos textos. Mas é no fluxo, no encadeamento desses escritos que o livro se dá.

\section{Minha proposta nesta resenha é a de identificar elementos que respondam a algumas questóes, pinçar, nos textos, parâmetros que sirvam para refletir sobre o que seria esse cinema gaúcho.}

A abertura do livro é feita pelo clássico texto Os pês- 
segos de Saint-Hilaire (Ensainho sobre o cinema gaúcho), de Damasceno, publicado pela primeira vez em 1972, mas que se mantém atual. Ele relata as tensões entre os grossos (que faziam cinema na época) e os intelectuais. Em nota de rodapé, Carlos Gerbase comenta o texto, e destaca que hoje essas divisões se mesclam e isso é visto no próprio livro, em que os autores produzem e pensam o cinema. Damasceno caracteriza o cinema gaúcho em semelhança não com Hollywood, mas com a aldeia de Tarascon (onde a fauna era paupérrima, mas os sujeitos tinham fama de grandes caçadores). No Rio Grande do Sul, apesar de não existir um cinema maduro, haveria muitos críticos e cineastas. Aí se dá a origem dessa divisão citada anteriormente: os poucos que produzem e os vários que criticam sem produzir.

\section{Freitas e Gerbase lançam} questóes que consideram importantes sobre o tema, como "o cinema gaúcho tem identidade própria? Ele já pode ser chamado de indústria, ou continua sendo um artesanato? Ainda tem sentido fazer cinema brasileiro longe do eixo Rio-Sáo Paulo?"

O autor entende os filmes feitos no Rio Grande do Sul, na época, como horríveis e superficiais, em sua maioria, mas reconhece que eles foram essenciais para a produção local que se constituiu. Os filmes dos quais ele fala seriam as chanchadas, consideradas por ele como a maior contribuição para o cinema gaúcho. Junto a esses filmes, se formaram os profissionais e o cinema gaúcho foi provando sua existência em um cenário local (com o reconhecimento da vasta audiência) e nacional. Os filmes de Teixeirinha, por exemplo, fariam parte de um movimento que construiu os alicerces da produção gaúcha e deveriam ser reconhecidos como tal.

Giba Assis Brasil, em Autores, cenas, espaços, dialoga explicitamente com o texto de Damasceno. Ele nos traz diferentes textos, de 1988, 1990 e 1993, revelando um processo pessoal de mudanças sobre a sua noção de cinema gaúcho. Aqui, faço um parêntese, ao entender que são dispensáveis os alertas de Giba Assis Brasil sobre as limitações do seu autodidatismo e sobre a superficialidade de suas reflexões. Digo isso porque é ele quem se preocupa explicitamente em problematizar a noção de cinema gaúcho, ele ilumina a questão e se propõe pensar a respeito.

Inicialmente ele procurava definir o cinema gaúcho por uma temática/abordagem recorrente (relatando que houve até quem dissesse que o cinema gaúcho fazia sempre os mesmos filmes), nascida de uma construção coletiva ("um modo porto-alegrense de fazer filmes, sintetizado na criação da Casa de Cinema" (p. 95)). Dois anos depois ele faz um resgate do cinema gaúcho dos anos 80 em termos institucionais, de influências, de realizações, experimentações, formação de profissionais, compreendendo que a década de 1980 terminou sem uma proposta estética globalizante, sendo a variedade o que marcava o cinema gaúcho.

O texto de 1993 dialoga com o de Damasceno, pensando que o ciclo do chimarrão e das bombachas se encerrou e o cinema não seria tão verde quanto os pêssegos de Saint Hilaire. Entretanto, ele coloca em xeque a existência de um cinema gaúcho em processo e não com episódios isolados. Essa concepção é influenciada pela proposição de Jean-Claude Bernardet, que disse negar a categoria de cinema gaúcho (esteticamente), já que ele "seria uma forma de expressão à procura de espaço" (p. 102). Sem dúvida, é interessante a colocação, mas nem por isso temos que aceitá-la sem experimentar a dúvida, mesmo que Bernardet seja um grande teórico do cinema brasileiro. Giba Assis Brasil, titubeando quanto à definição desse conceito, se pergunta ao final do texto "Mas definir para quê?" e no último parágrafo encerra dizendo que se estivermos ainda "construindo o espaço das imagens", os pioneiros filmes gaúchos serão o retrato do amadurecimento desse cinema. Ainda que a fala de Bernardet tenha inibido suas convicções, as primeiras concepções de Giba Assis Brasil, no sentido da existência de um cinema gaúcho, parecem se manter (mesmo que hesite em assumi-las).

Freitas, por sua vez, em De Kafka ao cinema americano: 3 efes, a experiência gaúcha de um minor movie, resolve a questão do cinema gaúcho apoiada no localismo, ou seja, ela refere-se "a produção cinematográfica realizada no Rio grande do Sul". Possivelmente porque essa é uma das características dos minor movies ("cinema menor", "minoria dentro da maioria", menos preocupado com grande estilo e com as metáforas), o localizado, o particular e não o universal. Ela nos aproxima do conceito de minor movies, reconhecendo um de seus exemplares no Rio Grande do Sul, o filme 3 efes, de Carlos Gerbase, que teria essas características. Os elementos criativos e estéticos desse exemplar do cinema gaúcho são vistos em articulação com tendências literárias e cinematográficas de um movimento mundial.

São vários os textos que abordam o cinema gaúcho nesse tensionamento com um contexto maior. Escosteguy e Romanoff, em As reabilitações do popular na voz do sujeito ordinário, vêem a presença do comum, do popular também em filmes feitos no Rio Grande do Sul. É 
o estabelecimento de comparações com um fenômeno mais amplo que vem na contramão da supervalorização e da superexposição de anônimos na mídia. A partir da análise de Kylmair (2005) e Esta não é sua vida (1991), a proposta se apresenta localmente, mas estabelece relações com um movimento mais amplo de "representação de vidas ordinárias" (p. 145). Os sujeitos dos documentários citados são retratados não como excepcionais, mas como sujeitos de si próprios.

Ainda nessa noção de contexto (entendido não como exterior, mas como intrínseco ao processo), mas trazendo para um cenário nacional, vejo articulados os textos Confusões, entraves, desafios na história da Fábrica Guarany, de Póvoas, e Amor que redime: reconstituição do pioneirismo do cinema gaúcho, de Stigger - não só por uma retomada histórica, mas por uma relação entre cinema gaúcho e cinema brasileiro. Póvoas, ainda que se preocupe com esclarecimentos e questões sobre a Fábrica Guarany, tem uma proposta importante, mas pouco explorada no texto, que seria a de incluir a produção gaúcha na chama Bela Época do Cinema Brasileiro, problematizando e colocando em xeque os chamados Ciclos Regionais. Ou seja, considerar as produções gaúchas de Eduardo Hirtz (1909-1912) e da Guarany (1912-1913) nesse contexto, ampliando o conceito de Bela Época do Cinema Brasileiro.

\section{O cinema gaúcho é pensado} em relação a uma produção em determinado espaço geográfico; a um contexto nacional e mundial; a um cinema da década de 1980 com uma estética própria; é definido a partir das equipes de profissionais locais; das locações que se passam na capital/ pampa/litoral; em relação a preocupações com escolhas nos diálogos e a especificidades de

\section{um mercado.}

Stigger, por sua vez, também articula a produção local com o cenário nacional. Ela traz o olhar dos críticos Pedro Lima e Adhemar Gonzaga (das revistas Paratodos,
Selecta, Cinearte) sobre o cinema gaúcho. Esses críticos seriam defensores dos filmes "posados" (de enredo), que durante a década de 1920 são feitos em várias partes do país, inclusive no Rio Grande do Sul. A defesa seria no sentido de que esses filmes agradavam o gosto popular e incentivavam a indústria cinematográfica brasileira. Os críticos relatavam as novidades sobre os ciclos regionais e buscavam uma unificação dos cineastas do país.

Entretanto, os filmes gaúchos muitas vezes eram perseguidos por esses críticos, que os consideravam ruins e amadores. O ponto que desperta a curiosidade da autora em escrever tal texto é o de perceber que o filme Amor que redime recebia muitos elogios, diferentemente dos demais. Aqui temos a visão do "estrangeiro" definindo o que seria o cinema feito no Rio Grande do Sul. Se por um lado seria o ruim e o amador, por outro, Amor que redime representa o progresso para o cinema brasileiro e a contribuição gaúcha para tal. (Além disso, só a história de Kerrigan, o malandro/herói que circulava pelos ciclos regionais, já renderia um belo artigo).

Os textos de Souza Abrindo a caixa preta: o trajeto de adaptação de O Louco de Cati e de Haussen, Deu pra ti, anos 70 e Estudos Culturais: juventude e representação do social, dialogam no sentido de pensar as condições de produção, os processos produtivos e as marcas dos sujeitos realizadores nos filmes. Souza, ao fazer um relato pessoal sobre como surge o filme A última estrada da praia, nos fala de um cinema gaúcho influenciado por um cinema mundial, repleto de referências de diretores que marcaram a sua trajetória e de sua equipe em relação ao consumo de filmes.

Haussen, preocupada com o imaginário relacionado a juventude gaúcha que se expressa no filme Deu pra ti, anos 70 (tanto no filme e quanto no seu processo de realização), nos revela a feitura e quem eram os sujeitos envolvidos. Relata as influências daquele período, o cotidiano, os grupos, a crítica ao momento político, os filmes, as músicas, a literatura, as práticas globalizadas de consumo que marcaram aquela juventude (dos realizadores e a retratada no filme, mas que se mesclam). Além disso, mostra a forma produtiva independente do cinema gaúcho, que implicava em parcerias com grupos teatrais e músicos, assim como a proposta de co-autoria e direção. As dificuldades de produção (equipamentos, orçamento, estrutura profissional) contribuíram para a constituição de uma estética característica do período, com destaque para a originalidade. O filme seria marcado por uma narrativa não-linear, que mistura ficção e fatos reais, planos longos, cortes secos, que a autora define em comparação dizendo que "estaria longe de ser uma superprodução hollywoodiana". Surgiria aí um cinema da década de 1980 com uma estética própria, consequência do Super-8 e do improviso para resolver as limitações.

Gerbase, em O uso da segunda pessoa na realização audio- 
visual do Rio Grande do Sul: o local e o universal, ao pensar sobre as escolhas em relação à fala dos personagens, nos revela escolhas estéticas, culturais, assim como um modo do cineasta colocar-se no filme. Além de uma discussão sobre o público ao qual o filme se destina e sobre o mercado em que o filme deve circular. Se na década de 80 havia uma matriz estética para o linguajar ("tu foi"), nos anos que seguem, outras formas aparecem. Essa diversidade de opções estéticas da produção da pós-retomada (e também na televisão) expressaria que o cinema gaúcho não tem uma identidade determinada (citando novamente a fala de Jean-Claude Bernardet, que parece ter marcado os realizadores/intelectuais gaúchos). Ele conclui referindo-se ao fato de que cada filme teria suas circunstâncias e razões para escolher as formas de representar os diálogos. A tensão entre o local e o universal expressaria a "necessidade (ou não) do realizador colocar-se existencialmente na tela" (p. 127).

\section{Entendo que esses elementos} permitem a constituição de uma identidade própria, múltipla e dinâmica; uma indústria que vai se constituindo considerando toda a problemática de um cenário nacional. [...] Vamos continuar discutindo, pensando, publicando e, especialmente, fazendo circular, como o próprio cinema gaúcho precisa

Barone, por sua vez, em Cinema gaúcho: uma panorâmica institucional, pensa o cinema gaúcho em termos de mercado, tecnologia, relações entre estruturas, agentes e instituições. Resgata a existência de fundações, associações de profissionais, prêmios, leis de incentivo, centro tecnológico, necessidade de preservação do patrimônio audiovisual, cursos de formação, produtoras, projetos de exibição, formas de produção, distribuição e de exibição, ou seja, elementos que constituem o meio ambiente em que "vive" e que "constituiu" o cinema gaúcho. Barone também resolve a expressão cinema gaúcho como "um campo relativamente separado do Cinema brasileiro e da própria cultura do Rio Grande do Sul e progressivamente vai sendo substituída por um concei- to de audiovisual gaúcho" (p. 166). O autor aponta para a necessidade de se considerar o cinema dentro de um campo maior, que seria o audiovisual e o articula com toda a problemática da produção-distribuição-exibição existente no cenário nacional, como o aumento da produção e a escassa circulação dos produtos audiovisuais.

Por fim, retomando as questões do início, me parece que o cinema gaúcho é pensado no livro em relação a uma produção em determinado espaço geográfico (Rio Grande do Sul, com elementos de uma cultura retratados); em articulação com um contexto nacional (um resgate histórico pensando a Bela Época do cinema brasileiro, os filmes posados, a crítica de cinema (ruim, amador, bom/ contribuição para o cinema nacional)) e com o cinema mundial (minor movies, popular/ordinário, inspirações/ referências no processo produtivo); a um cinema da década de 1980 com uma estética própria (conseqüência do Super-8 e improvisação para resolver as limitações) ou uma estética marcada pela variedade; definido a partir das equipes de profissionais locais (um modo portoalegrês de fazer cinema); das locações que se passam na capital/ pampa/litoral; em relação a preocupações com escolhas nos diálogos; especificidades de um mercado (que sofre como o cinema brasileiro em geral).

Entendo que esses elementos permitem a constituição de uma identidade própria, múltipla e dinâmica; uma indústria que vai se constituindo considerando toda a problemática de um cenário nacional. E me parece que sim, há vários motivos para produzir fora de um eixo Rio-São Paulo, associando-se isto a um pensamento sobre essa produção e sobre as diferentes formas de expressão audiovisual, como os organizadores atentam já na apresentação. Vamos continuar discutindo, pensando, publicando e, especialmente, fazendo circular, como o próprio cinema gaúcho precisa Famecos 